\title{
Improvement in Comprehensive Properties of Poly(Methyl Methacrylate)-Based Gel Polymer Electrolyte by a Core-Shell Poly(Methyl Methacrylate)-Grafted Ordered Mesoporous Silica
}

\author{
Lixin Xu, Feng Xu, Feng Chen, Jintao Yang, and Mingqiang Zhong \\ College of Chemical Engineering and Materials Science, Zhejiang University of Technology, No. 18, Chaowang Road, 6th Zone, \\ Chaohui, Hangzhou 310014, China
}

Correspondence should be addressed to Mingqiang Zhong, zhongmingqiang@hotmail.com

Received 2 March 2011; Accepted 7 April 2011

Academic Editor: Sherine Obare

Copyright $\odot 2012$ Lixin Xu et al. This is an open access article distributed under the Creative Commons Attribution License, which permits unrestricted use, distribution, and reproduction in any medium, provided the original work is properly cited.

A novel strategy, herein, is demonstrated for improving comprehensive properties of poly (methyl methacrylate)(PMMA)-based gel polymer electrolyte (GPE) with a core-shell PMMA-grafted ordered mesoporous silica (OMS-g-PMMA). The OMS-g-PMMA was synthesized by surface-initiated atom transfer radical polymerization of methyl methacrylate from the exterior surface of OMS particle. A series of PMMA-based GPE membrances, filled with the OMS-g-PMMA of different contents, were further prepared by solution casting technique. The OMS-g-PMMA was confirmed to possess regular core-shell structure, in which a PMMA shell is chemically grafted to the exterior surface of silica core remaining intact mesoporous characteristics. Compared to the bare OMS, the OMS-g-PMMA is found to more effectively improve the comprehensive properties of PMMA-based GPE including ionic conductivity, thermal stability, and mechanical properties as well. For the PMMA-based GPE filled with 15 phr OMS-g-PMMA, the ionic conductivity at $25^{\circ} \mathrm{C}$ reaches $1.59 \times 10^{-4} \mathrm{~S} \cdot \mathrm{cm}^{-1}$, which is higher by nearly two orders than that of the corresponding filler-free parent GPE. Meanwhile, the tensile strength and Young's modulus increase by 2.39 and 2.41 times, respectively, with an improvement in glass-transition temperature $\left(T_{g}\right)$ about $10^{\circ} \mathrm{C}$. The excellent comprehensive properties make the PMMA-based GPE filled with OMS-g-PMMA as potential candidate for electrochemical devices.

\section{Introduction}

Polymer electrolytes with excellent comprehensive properties have been attracting considerable attention in recent years with increasing demands for safe, lightweight lithium ion batteries, and various electrochemical devices of high performance. A great number of strategies, so far, have been explored for optimizing properties of polymer electrolytes, typically such as modification by adding plasticizers [15], and inorganic fillers [6-10]. Among them, impregnating plasticizer into polymer matrix to form gel polymer electrolyte (GPE) is one of the widely adopted approaches, since GPE combines the advantages of liquid electrolytes with higher ionic conductivity and solid electrolytes without leakage [11]. Nevertheless, GPE usually exhibits poor mechanical properties and thermal instability owing to the existence of plasticizer, which is the major hindrance to their various practical applications. Although many methods have been successfully demonstrated for improving certain single property of GPE, it is still a challenge to develop GPE with excellent comprehensive performance including higher ionic conductivity, better mechanical properties and improved thermal stability as well.

One of the preferable solutions to above challenge is to incorporate inorganic nanosized fillers, such as $\mathrm{SiO}_{2}[3,7,8]$, $\mathrm{Al}_{2} \mathrm{O}_{3}[6,12], \mathrm{TiO}_{2}[6,13]$, and layered clays [11], into GPE to form nanocomposite GPE (NGPE). It has been reported that the introduction of some inorganic nanosized fillers could lead to an improvement both in ionic conductivity and in other properties including mechanical strength and thermal stability $[3,11,12]$. The role of inorganic nanosized fillers in improving ionic conductivity of GPE is usually attributed to the Lewis acid-base interaction between the polar surface of fillers and ionic species, which yields more 
mobile ion species, and thus leads to an improvement in ionic conductivity $[14,15]$. In addition, some surface groups of inorganic nanosized fillers may provide physical crosslinking centers [16], and thus can improve, to an extent, the mechanical properties and thermal stability of GPE. Obviously, it is of great importance for NGPE to ensure a homogeneous dispersion of inorganic nanosized fillers in matrix for the above roles depend largely on the particle size and surface status of fillers. However, aggregation is usually inevitable in polymer matrix for the bare inorganic nanosized fillers due to their higher specific surface area and poor interfacial compatibilization with polymer matrix. Although the dispersibility of inorganic nanosized fillers in polymer matrix could be improved by surface modification with organic moieties such as coupling agent or polymer, the modified surface status of fillers usually leads to the dissociation of Lewis acid-base complex between the surface of fillers and ionic species, which is unfavorable to the improvement in properties of GPE.

We herein explore a novel strategy for improving comprehensive properties of poly(methyl methacrylate) (PMMA)-based GPE by using a core-shell PMMA-grafted ordered mesoporous silica (OMS-g-PMMA) as filler. The OMS-g-PMMA possesses a PMMA shell, which is chemically grafted to the exterior surface of ordered mesoporous silica (OMS) as a core remaining intact mesoporous structure. The PMMA shell is expected to greatly improve the interfacial interaction between the OMS and PMMA matrix, and thus to impart the modified GPE with highly improved mechanical properties and thermal stability. Moreover, the silica core has ordered and tunable pore channels with larger surface area and abundant surface $-\mathrm{OH}$, which is beneficial to the formation of Lewis acid-base interactions between fillers-ions and thus to the improvement in ionic conductivity of GPE. Although a large volume of research papers on application of OMS as fillers in composite polymer electrolyte (CPE) [10,17-21] are available, researches related to the effect of core-shell polymer-grafted OMS hybrid particle as fillers in GPE are still scarce. In this research, the OMS-g-PMMA was synthesized by surface-initiated atom transfer radical polymerization (ATRP) of methyl methacrylate from the exterior surface of OMS particle and the PMMA-based GPE was prepared by solution casting technique using the OMS-g-PMMA as filler, $\mathrm{LiClO}_{4}$ as salt and propylene carbonate (PC) as plasticizer. The structure of the OMS-g-PMMA was characterized and the role of it in improving comprehensive properties of PMMA-based GPE was assessed.

\section{Experimental Section}

2.1. Materials. Propylene carbonate (PC, >99.5\%) and 2-bromoisobutyryl bromide ( $>98 \%)$ were purchased from Acros Organics. 3-Aminopropyltriethoxysilane (APTEOS, $>98 \%)$ was supplied from J\&K Chemical Ltd. $\mathrm{CuBr}(>98 \%)$ was obtained from Strem Chemicals Inc. $N, N, N, N^{\prime}, N^{\prime \prime}-$ pentamethyl-diethylenetriamine (PMDETA, >98\%) was from Tokyo Chemical Industry Co., Ltd. Cetyltrimethy- lammonium bromide (CTAB, analytical grade) was purchased from Shanghai Bo'ao Biological Technology Co., Ltd. Tetraethyl orthosilicate (TEOS, analytical grade) and triethylamine ( $>98 \%$ ) was from Shanghai Chemical Reagent Purchase and Supply Wulian Chemical Factory. $\mathrm{LiClO}_{4}$ was supplied from Aladin Chemical Reagent Inc. of Shanghai, China. Poly (methyl methacrylate) (PMMA) as a matrix was obtained from Zhenjiang Qimei Chemical Industry Co., Ltd. All above reagents/materials were used as received. Methyl methacrylate (MMA, analytical grade) was purchased from Quzhou Juhua Chemical Reagents Ltd. and purified by distillation under reduced pressure prior to use.

2.2. Synthesis of Core-Shell OMS-g-PMMA Particles. The strategy for synthesizing core-shell OMS-g-PMMA is schematically illustrated in Figure 1. To synthesize the OMS containing template ( $t$ OMS), $1.0 \mathrm{~g}$ CTAB as a template was first dissolved in $500 \mathrm{~mL}$ deionized water, and then, $4 \mathrm{~mL}$ $\mathrm{NaOH}$ aqueous solution $(2 \mathrm{M})$ was added. The solution was heated to $80^{\circ} \mathrm{C}$ upon stirring and subsequently $20 \mathrm{~mL}$ TEOS was added dropwise within $0.5 \mathrm{~h}$. The reaction was further lasted at $80^{\circ} \mathrm{C}$ for $4 \mathrm{~h}$ and a white suspension was gradually formed. The suspension was filtrated and the resulting precipitate was washed thoroughly with methanol, followed by drying at ambient temperature for $8 \mathrm{~h}$ in vacuum to give the $t$ OMS.

The resulting $t$ OMS was subsequently modified with a coupling agent, APTEOS, to give the amine groupfunctionalized $t$ OMS ( $t$ OMS- $\mathrm{NH}_{2}$ ). $4.0 \mathrm{~g} t$ OMS was dispersed in $600 \mathrm{~mL}$ toluene containing $10.9 \mathrm{~g}$ APTEOS by sonication for $1 \mathrm{~h}$ in a dried $1000 \mathrm{~mL}$ flask. The reaction was lasted for $24 \mathrm{~h}$ under reflux upon stirring. The solid product was collected by centrifugation and washed with methanol ( $40 \mathrm{~mL} /$ time) for 2 times, followed by drying at $50^{\circ} \mathrm{C}$ for $8 \mathrm{~h}$ in vacuum to give the $t$ OMS- $\mathrm{NH}_{2}$.

The ATRP initiator, 2-bromoisobutyryl bromide, was further used to react with the $t$ OMS- $\mathrm{NH}_{2}$ to give the ATRP initiator-immobilized $t$ OMS ( $t$ OMS-Br). $2.0 \mathrm{~g} t$ OMS$\mathrm{NH}_{2}$ was dispersed in $300 \mathrm{~mL}$ anhydrous dichloromethane containing $2 \%$ triethylamine $(\mathrm{V} / \mathrm{V})$ by sonication in a dried $500 \mathrm{~mL}$ schlenk bottle. $20 \mathrm{~mL}$ 2-bromoisobutyryl bromide was subsequently added dropwise within $3 \mathrm{~h}$ under $\mathrm{N}_{2}$ protection at $0^{\circ} \mathrm{C}$. The reaction was lasted at r.t. for $30 \mathrm{~h}$, the resulting suspension was centrifuged, and the solid product was thoroughly washed with deionized water, acetone, and toluene, in sequence, followed by drying at r.t. for $8 \mathrm{~h}$ in vacuum to give the $t$ OMS-Br. The CTAB as a template contained in the $t$ OMS-Br was further removed by an extraction procedure with acidic ethanol and the OMS-Br without containing template was finally collected.

A typical ATRP procedure was performed to prepare the OMS-g-PMMA. 0.50 g dried OMS-Br, $0.03 \mathrm{~g} \mathrm{CuBr}, 1.0 \mathrm{~mL}$ PMDETA, $10.0 \mathrm{~mL}$ anhydrous toluene, and $5.0 \mathrm{~mL}$ MMA were added into a dried $100 \mathrm{~mL}$ schlenk bottle. The mixture was degassed through three freeze-pump-thaw cycles and finally filled with $\mathrm{N}_{2}$ atmosphere. The reaction was subsequently carried out at $80^{\circ} \mathrm{C}$ for $24 \mathrm{~h}$ under $\mathrm{N}_{2}$ protection. The solid product was obtained by centrifuging the suspension and was washed thoroughly with toluene and methanol, 
Ordered mesoporous silica containing CTAB template ( $t$ OMS)
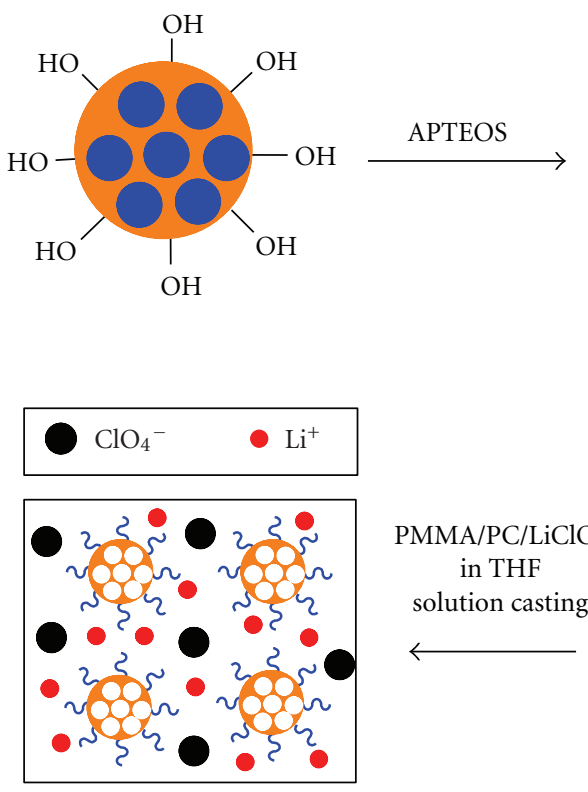

PMMA/PC/LiClO $4 / O M S$-g-PMMA gel polymer electrolyte membrane
Amine-group functionalized $t$ OMS $\left(t\right.$ OMS- $\mathrm{NH}_{2}$ )
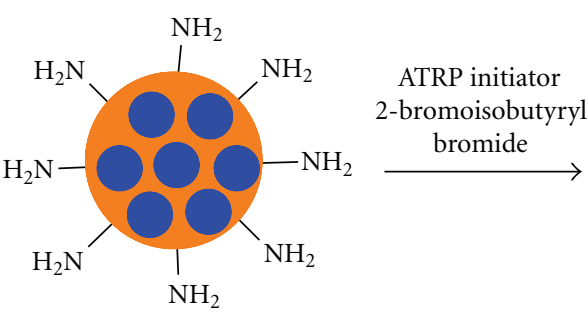<smiles>C1CCCCCCCCCCCC1</smiles>

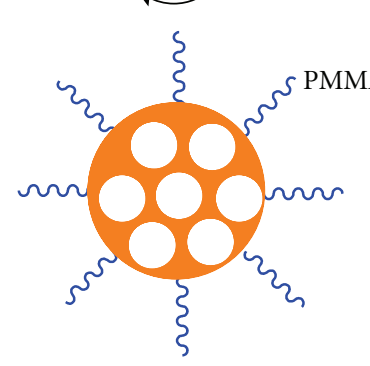

PMMA-grafted OMS (OMS-g-PMMA)
ATRP initiator group immobilized $t$ OMS ( $t$ OMS-Br)
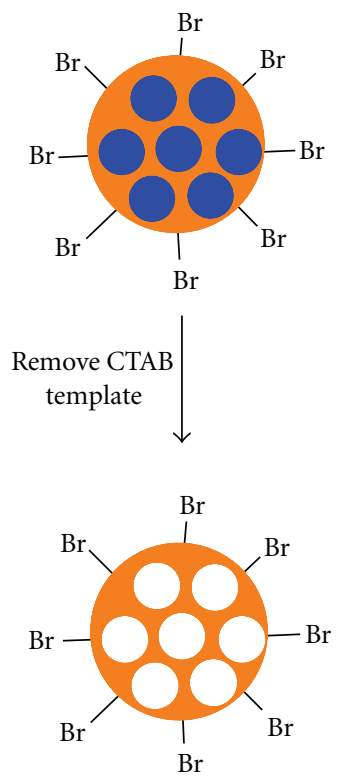

ATRP initiator immobilized OMS (OMS-Br)

FIGURE 1: The schematic illustration for the synthesis of OMS-g-PMMA and preparation of PMMA/PC/LiClO $4 /$ OMS-g-PMMA gel polymer electrolyte membrane.

respectively. The resulting powder was finally dried at $40^{\circ} \mathrm{C}$ for $24 \mathrm{~h}$ in vacuum, giving the OMS-g-PMMA.

2.3. Preparation of the PMMA-Based GPE Filled with the OMS-g-PMMA. The PMMA-based GPE filled with the OMS-g-PMMA was prepared by a solution casting technique. In a typical procedure, the synthesized OMS-gPMMA (5 20 mg) was first dispersed in $20 \mathrm{~mL}$ THF containing $30 \mathrm{mg} \mathrm{PC}$ and $50 \mathrm{mg} \mathrm{LiClO}_{4}$ by sonication for $1 \mathrm{~h}$, and then, the solvent was removed in vacuo to give a powderlike mixture, OMS-g-PMMA/PC/LiClO 4 (marked as I). The matrix, PMMA, was further dissolved in THF to form a 30 wt \% solution (marked as II). A series of PMMA-based GPE filled with the OMS-g-PMMA of different loading concentrations, PMMA/PC/LiClO $4 / \mathrm{OMS}$-g-PMMA (100/30/50/ $x$, $w / w / w / w, x$ changes from 0 to 20 ), were finally obtained by mixing I and II under sonication and subsequent drying at room temperature for $48 \mathrm{~h}$ in a PTFE mould. The $x$, herein, represents the actual weight of OMS in the OMS-g-PMMA, which can be calculated based on thermogravimetric analysis (TGA). For comparison, a series of PMMA-based GPE filled with the bare OMS, PMMA/PC/ $\mathrm{LiClO}_{4} /$ bare OMS $(100 / 30 / 50 / x, w / w / w / w, x$ changes from 0 to 20$)$, were also prepared through the similar procedure mentioned as above. For all the prepared GPE membranes, the average thickness is controlled at $\sim 0.20 \mathrm{~cm}$.
2.4. Characterization. Fourier transform infrared spectroscopy (FTIR) spectra were recorded on a Nicolet 6700 FTIR spectrometer. All samples were prepared as pellets using spectroscopic grade $\mathrm{KBr}$ in a presser. TGA was performed on a SDT Q600 thermogravimetry analyzer. Measurements were carried out under $\mathrm{N}_{2}$ protection from $25^{\circ} \mathrm{C}$ to $800^{\circ} \mathrm{C}$ at a heating rate of $20^{\circ} \mathrm{C} / \mathrm{min}$. High-resolution transmittance electron microscopy (HRTEM) analysis was performed on a $300 \mathrm{kV}$ JEM-100 CX II transmittance electron microscope. TEM samples were prepared by dispersing little sample in ethanol and subsequent depositing onto copper grids. Smallangle X-ray diffraction (SAXRD) analysis was carried out using an XD-98 diffractometer with $\mathrm{Cu}$ irradiation $(36 \mathrm{kV}$, $30 \mathrm{~mA}$ ) at ambient temperature. The scanning rate is $2.0^{\circ} / \mathrm{min}$ for all samples with a step size of $0.02^{\circ}$. Differential scanning calorimetry (DSC) curves were obtained on a DSC Q100 instrument equipped with a refrigerated cooling system (RCS) under $\mathrm{N}_{2}$ atmosphere. Samples were heated from $40^{\circ} \mathrm{C}$ to $200^{\circ} \mathrm{C}$ at $50^{\circ} \mathrm{C} / \mathrm{min}$ and then cooled to $40^{\circ} \mathrm{C}$ at $20^{\circ} \mathrm{C} / \mathrm{min}$ to eliminate heating history. Then, the data was recorded on the second heating from $40^{\circ} \mathrm{C}$ to $200^{\circ} \mathrm{C}$ at $20^{\circ} \mathrm{C} / \mathrm{min}$. For all samples, the glass transfer temperature $\left(T_{g}\right)$ was read as the middle of the change in heat capacity. The mechanical properties of PMMA-based GPE were tested on a CMT 5104 universal materials mechanics tester at ambient temperature. The crosshead speed was controlled at $15 \mathrm{~mm} / \mathrm{min}$. The test samples were designed as rectangular 
pieces with a dimension of $2.5 \mathrm{~cm}$ (length) $\times 1.1 \mathrm{~cm}$ (width) $\times 0.1 \sim 0.3 \mathrm{~cm}$ (thickness). The ionic conductivity of PMMAbased GPE was determined by alternating current (AC) impedance analysis on a CHI 650B electrochemical workstation. The measurements were carried out using an electrochemical cell consisting of polymer electrolyte membrane sandwiched between two stainless steel electrodes in a frequency range of $10 \mathrm{~Hz}$ to $0.1 \mathrm{MHz}$ over a temperature range of $298 \sim 353 \mathrm{~K}$ at a relative constant humidity. The ionic conductivity was calculated by

$$
\sigma=\frac{1}{R_{b}} \times \frac{d}{S}
$$

where $d$ is the thickness of electrolyte membrane; $S$ is the contact area between electrode and electrolyte membrane; $R_{b}$ is the bulk impedance of electrolyte membrane. In this research, the $R_{b}$ was fitted through a Zplot software according to the equivalent circuit of impedance data.

\section{Results and Discussion}

3.1. Structure Characterization of the OMS-g-PMMA. As schematically illustrated in Figure 1, the core-shell PMMAgrafted OMS hybrid particle was synthesized by surfaceinitiated ATRP based on a literature method [22]. The OMS remaining template ( $t$ OMS) was first synthesized by sol-gel method and then modified with a coupling agent, APTEOS, to give the amine group-functionalized $t$ OMS ( $t$ OMS$\mathrm{NH}_{2}$ ). The ATRP initiator, 2-bromoisobutyryl bromide, was further chemically immobilized onto the exterior surface of OMS by reacting with the amine group from the $t$ OMS$\mathrm{NH}_{2}$ and the ATRP initiator-immobilized OMS (OMS-Br) was obtained by removing the template contained in the $t$ OMS-Br through an extraction procedure. The core-shell PMMA-grafted OMS was thus expected to be obtained by using the resulting OMS-Br as substrate for subsequent surface-initiated ATRP of MMA. The structure of the synthesized OMS-g-PMMA was characterized by FTIR, TGA, HRTEM, and SAXRD analysis, respectively.

Figures 2(a)-2(c) illustrates and compares the FTIR spectra of the bare OMS, OMS-Br, and OMS-g-PMMA sample. The peaks at $1087 \mathrm{~cm}^{-1}, 1637 \mathrm{~cm}^{-1}$ and $3400 \mathrm{~cm}^{-1}$ can be clearly observed for all the spectra. Among them, the peak at $1087 \mathrm{~cm}^{-1}$ originates from the Si-O stretching vibration in the bulk silica and the peaks at $1637 \mathrm{~cm}^{-1}$ and $3400 \mathrm{~cm}^{-1}$ are usually attributed to the adsorbed water on the surface of silica particles. In the spectrum (Figure 2(b)) of the ATRP initiator-functionalized OMS, OMS-Br, two weak peaks at $2854 \mathrm{~cm}^{-1}$ and $2928 \mathrm{~cm}^{-1}$, characteristic of alky C-H stretching vibration modes, are found, while they are absent in that (Figure 2(a)) of the bare OMS, indicating that the ATRP initiator, 2-bromoisobutyryl bromide, has been covalently immobilized onto the OMS particles. The stronger peak at $1735 \mathrm{~cm}^{-1}$ in the spectrum (Figure 2(c)) of the purified OMS-g-PMMA should be assigned to the $\mathrm{C}=\mathrm{O}$ stretching vibration associated with the ester group from the grafted PMMA. In addition, two peaks at $2946 \mathrm{~cm}^{-1}$ and $2850 \mathrm{~cm}^{-1}$, characteristic of alky C-H stretching vibration, are also found

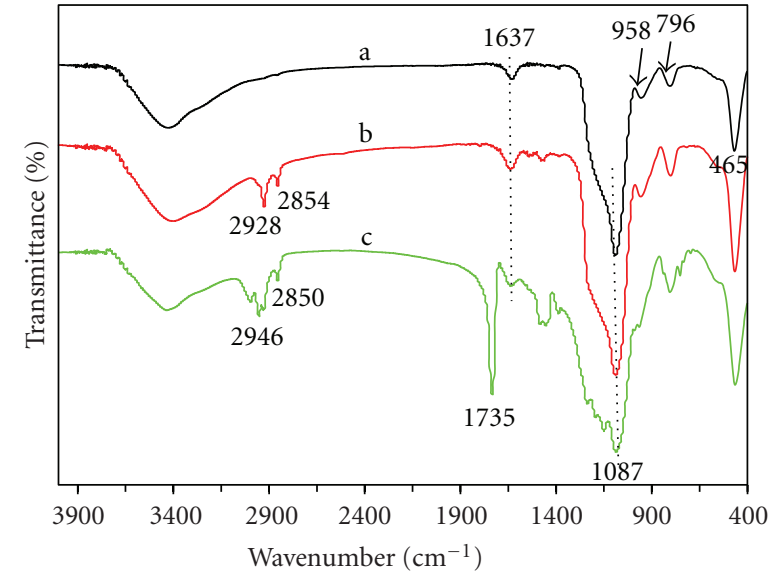

FIGURE 2: Fourier transform infrared (FTIR) spectra of the bare OMS (a), OMS-Br, (b) and OMS-g-PMMA (c).

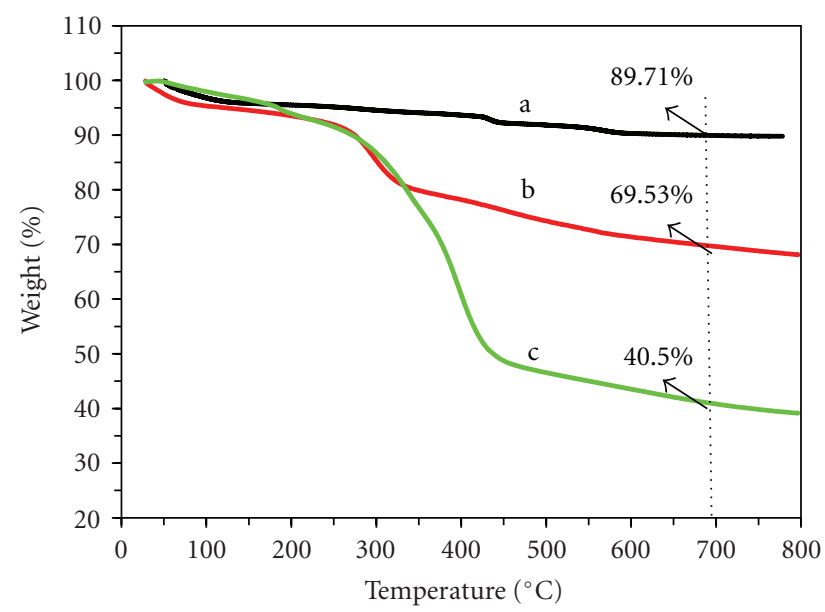

FIgURE 3: Thermogravimetry analysis (TGA) curves of the bare OMS (a), OMS-Br, (b) and OMS-g-PMMA (c).

in above spectrum, corresponding to the added alky groups from the grafted PMMA. These indicate that PMMA chains have been chemically bonded to the surface of OMS particles.

The TGA curves for the above three samples are shown in Figures 3(a)-3(c). A mass loss at $700^{\circ} \mathrm{C}$ about $10.29 \%$ is found for the bare OMS, which might be due to the loss of associated water and remaining CTAB template. Compared to the bare OMS, the mass loss at $700^{\circ} \mathrm{C}$ for the OMS- $\mathrm{Br}$ increases from $10.29 \%$ to $30.47 \%$, due to the introduction of chemically bonded coupling agent and ATRP initiator groups. The mass loss at $700^{\circ} \mathrm{C}$ further increases to $59.50 \%$ for the OMS-g-PMMA, indicating that PMMA chains have been covalently grafted to the surface of OMS particles. Taking the mass loss at $700^{\circ} \mathrm{C}$ as reference, the grafting ratio of PMMA in the OMS-g-PMMA could be calculated to be $0.99 \mathrm{~g}$ PMMA/g OMS by assuming that all the organic moieties were lost at $700^{\circ} \mathrm{C}$.

The morphology of the bare OMS and OMS-g-PMMA particles was characterized by using HRTEM technique. 


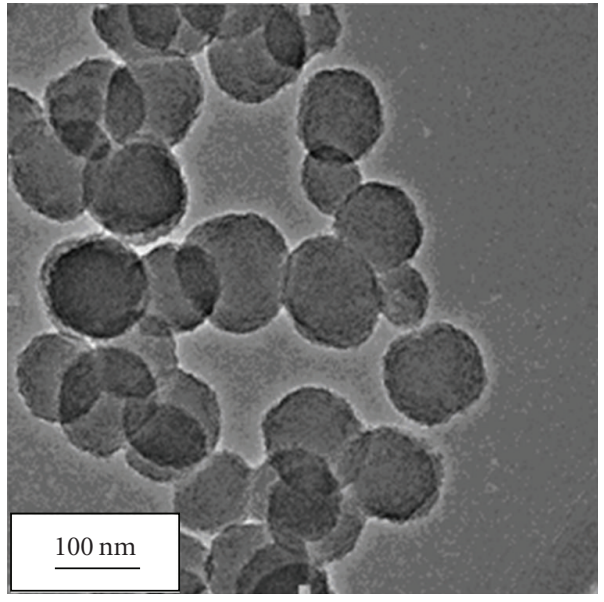

(a)

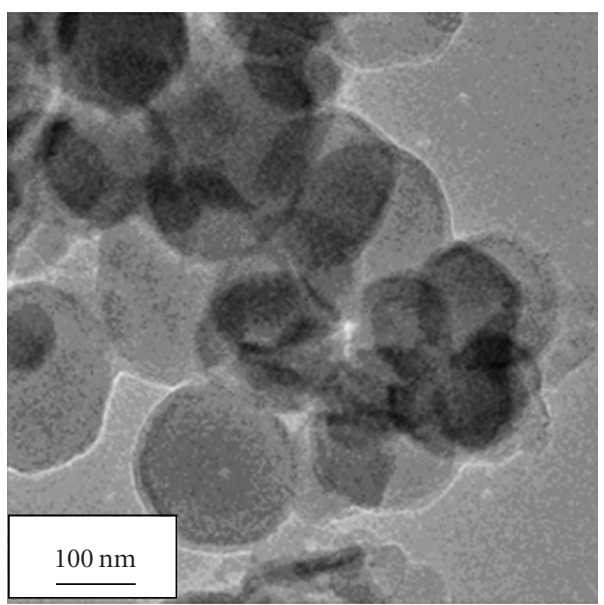

(c)

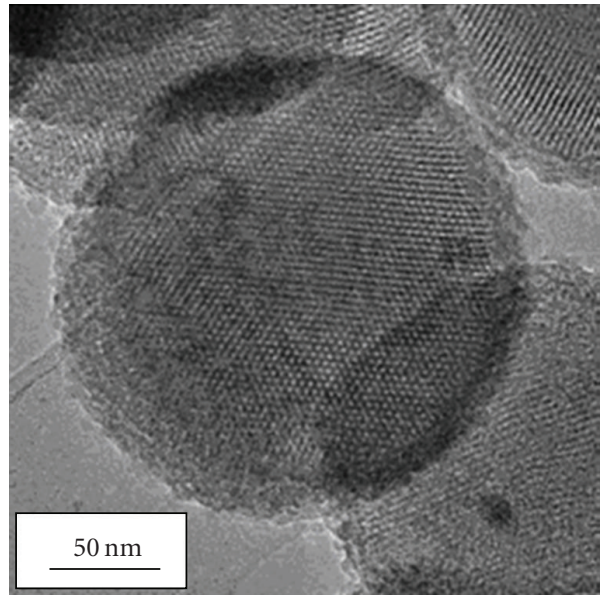

(b)

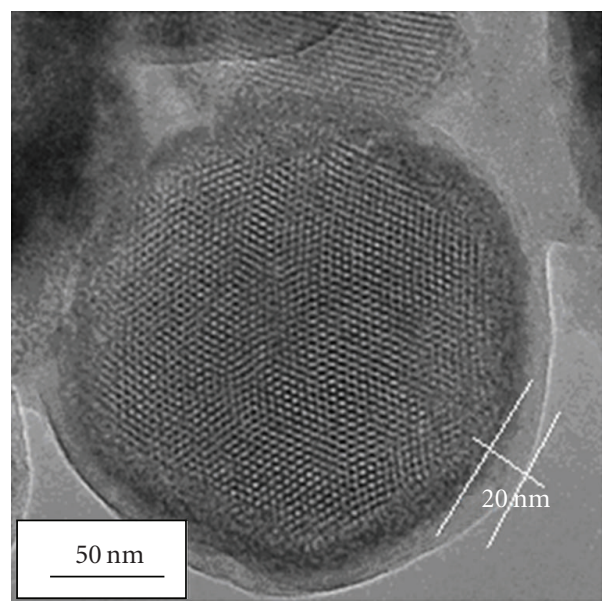

(d)

Figure 4: High-resolution transmittance electron microscopy (HRTEM) images of the bare OMS ((a), (b)) and OMS-g-PMMA ((c), (d)).

Figures 4(a) and 4(b) shows the HRTEM images of the bare OMS. It can be observed that the bare OMS particles exhibit a roughly spherical shape with an average diameter about $100 \mathrm{~nm}$ (Figure 4(a)). In addition, the hexagonally packed dots and parallel stripes are obvious for the bare OMS as shown in Figure 4(b), indicating a typical MCM-41 type mesoporous channel structure. The average pore size of the bare OMS is about $3 \sim 4 \mathrm{~nm}$ (Figure $4(\mathrm{~b})$ ), which is comparable to that $(3.5 \mathrm{~nm})$ determined by $\mathrm{N}_{2}$ adsorption testing. Figures 4(c) and 4(d) shows the HRTEM images for the OMS-g-PMMA. A smooth PMMA shell around the exterior surface of OMS particle, as a core, could be clearly found with an average shell thickness about $20 \mathrm{~nm}$ (Figure 4(d)). Moreover, it is also clear that the ordered mesoporous structure of the OMS core is still intact after surface modification by surface-initiated ATRP of MMA.

Figures 5(a) and 5(b) shows the small-angle X-ray diffraction patterns of the bare OMS and OMS-g-PMMA. The XRD pattern for the bare OMS (Figure 5(a)) exhibits an intense peak at $2 \theta=2.148^{\circ}$, which is usually associated with the (100) diffraction when a hexagonal cell is assumed [23].
In addition, two weak peaks, in the region of $2 \theta=3.5 \sim 4.5^{\circ}$, is also found in the above pattern, which can be indexed as the (110) and (200) diffractions. These confirm that the synthesized OMS has a typical MCM-41 type ordered mesoporous channel structure. As shown in Figure 5(b), the XRD pattern for the OMS-g-PMMA is similar to that of the bare OMS, indicating a remaining intact hexagonal array of the pores in the OMS core after the surface-initiated ATRP of MMA.

3.2. Ionic Conductivity Properties. To examine the effect of the resulting core-shell OMS-g-PMMA on improving the ionic conductivity of PMMA-based GPE, two types of GPE including PMMA/PC/LiClO $4 / \mathrm{OMS}$-g-PMMA and PMMA/ $\mathrm{PC} / \mathrm{LiClO}_{4} /$ bare OMS were prepared, respectively, with different filler-loading contents by a solution casting technique. The ionic conductivity of the resulting GPE was subsequently determined and compared by AC impendence analysis method. Figure 6 shows the impendence plots for the GPE, PMMA/PC/LiClO $4 / \mathrm{OMS}$-g-PMMA (100/30/50/15, 


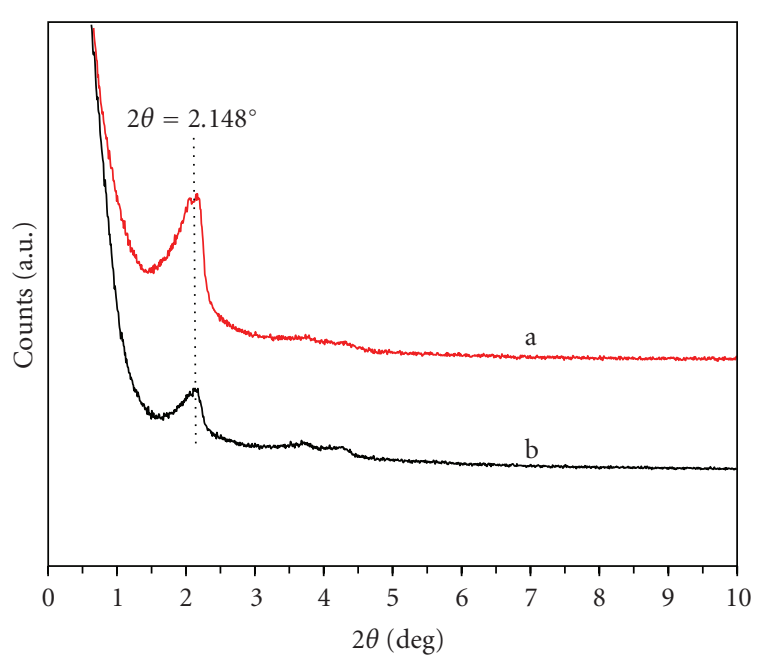

FIGURE 5: Small-angle X-ray diffraction (SAXRD) patterns of the bare OMS (a) and OMS-g-PMMA (b).

$w / w / w / w)$, at different temperature. It is shown that at a lower testing temperature, such as $25^{\circ} \mathrm{C}$ and $30^{\circ} \mathrm{C}$, the profile consists of a completely depressed semicircle in highfrequency range and a straight line inclined at a constant angle to the real axis in lower frequency range. The depressed semicircle is related to the conduction process, which corresponds to the bulk resistance, while the linear region is due to the effect of the blocking electrodes, corresponding to the interfacial impendence [6]. In addition, it is also found that the depressed semicircle disappeared gradually, in the higher temperature range $\left(40 \sim 80^{\circ} \mathrm{C}\right)$, and only a linear region was shown in the lower frequency range, which might be due to the softening of GPE membrane at a higher temperature.

The ionic conductivity of various GPE membranes was further calculated by referring to (1), where the bulk resistance, $R_{b}(\Omega)$, could be determined as the abscissa of crossover of the high- and low-frequency curves in the impendence plot [1]. Figures $7(a)$ and $7(b)$ illustrates the temperature variation of the conductivity for two different types of PMMA-based GPE systems, PMMA/PC/ $/ \mathrm{LiClO}_{4} /$ bare OMS $(100 / 30 / 50 / x, w / w / w / w)$ and PMMA/PC/LiClO $4 / \mathrm{OMS}-g-^{-}$ PMMA $(100 / 30 / 50 / x, w / w / w / w)$, under different filler-loading contents. It can be seen that the conductivity for both systems shows the same dependence on the absolute temperature, increasing with the absolute temperature in a nonlinear relationship. This non-Arrhenius behavior indicates that the ion transport in above GPE systems is dependent on polymer segmental motion and thus can best be described by the Vogel-Tamman-Fulcher (VTF) equation (2) as follows:

$$
\sigma=A T^{-1 / 2} \exp \left[-\frac{B}{\left(T-T_{0}\right)}\right],
$$

where $A$ and $B$ are constants and $T_{0}$ is a reference temperature [2]. This equation is characteristic of amorphous polymeric electrolytes, which follows free-volume mode.

Figure 8 illustrates the variation trend of ionic conductivity as a function of filler-loading content for the PMMAbased GPE filled with the bare OMS and OMS-g-PMMA,

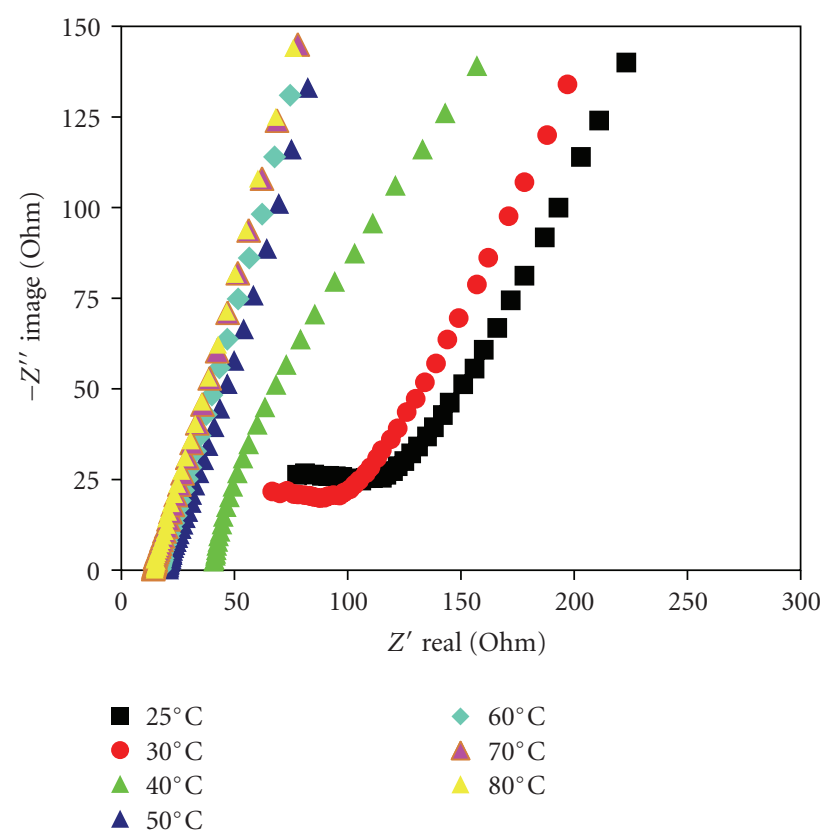

Figure 6: AC impendence spectra under different temperature of the PMMA-based GPE, PMMA/PC/LiClO $/ \mathrm{ClOMS}_{4}$-g-PMMA $(100 / 30 / 50 / 15, w / w / w / w)$.

respectively, in a temperature range of $25^{\circ} \mathrm{C}$ to $80^{\circ} \mathrm{C}$. The detailed conductivity data at $25^{\circ} \mathrm{C}$ are also listed in Table 1 for comparison. As can be seen the conductivity for the fillerfilled PMMA-based GPE demonstrates a general increasing trend compared to the parent GPE without doping with filler. The conductivity at $25^{\circ} \mathrm{C}$ is $1.17 \times 10^{-4} \mathrm{~S} \cdot \mathrm{cm}^{-1}$ and $1.59 \times 10^{-4} \mathrm{~S} \cdot \mathrm{cm}^{-1}$ for the $\mathrm{PMMA} / \mathrm{PC} / \mathrm{LiClO}_{4} /$ bare OMS $(100 / 30 / 50 / 15, w / w / w / w)$ and PMMA/PC/LiClO $4 / \mathrm{OMS}_{4}$ PMMA $(100 / 30 / 50 / 15, w / w / w / w)$ membrane, respectively, which are remarkably higher than that of their parent GPE $\left(4.76 \times 10^{-6} \mathrm{~S} \cdot \mathrm{cm}^{-1}\right)$ by nearly two order of magnitude. Such an increase in conductivity is maybe due to an additional ion-conducting pathway besides the cooperation interaction between PMMA segment and $\mathrm{Li}^{+}$cations. The additional ion-conducting pathways may be ascribed to the cooperation interaction between the silicon $\mathrm{O}$ atoms of OMS and $\mathrm{Li}^{+}$cations, as well as the characteristic orderly packed channels of OMS, which is maybe helpful for transmitting $\mathrm{Li}^{+}$cations by imbedding PMMA and PC into pores. In addition, it is obvious as shown in Figure 8(a) that the conductivity, for the bare OMS filled system, increases with increasing the OMS filler-loading content and reaches a maximum value when the filler-loading content is $15 \mathrm{phr}$ and then begins to decrease. This trend is especially obvious at a lower temperature such as $25^{\circ} \mathrm{C}, 30^{\circ} \mathrm{C}$, and $40^{\circ} \mathrm{C}$. This trend is likely due to the poor interfacial compatibilization between the bare OMS and PMMA matrix, which results in marked aggregation under a higher OMS filler-loading content. As a result, the conductivity of system decreases with further increasing filler-loading content due to the agglomeration of OMS into larger particles, by which the $\mathrm{Li}^{+}$transferring will be obstructed. 


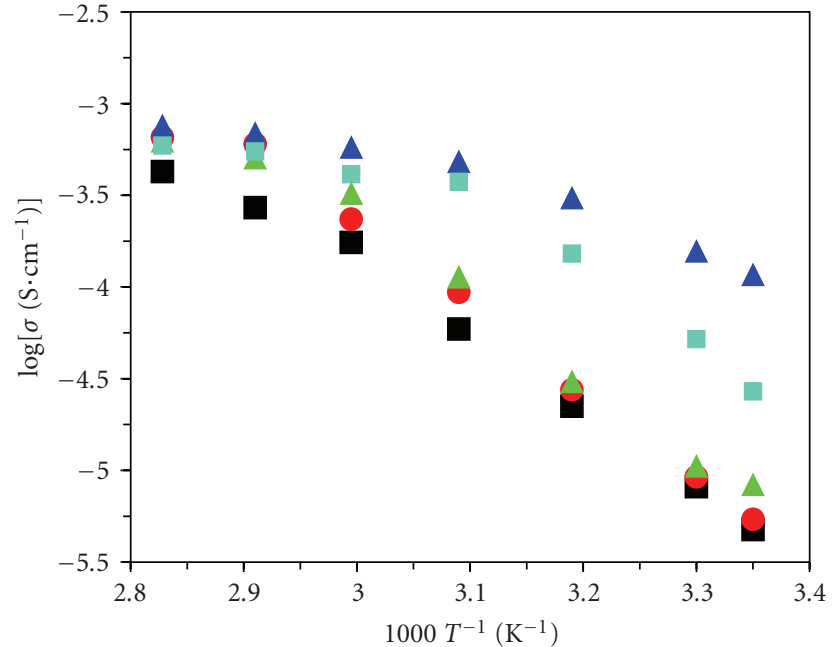
- $x=0$
- $x=5$
A $x=15$
- $x=20$

$\Delta x=10$

(a)

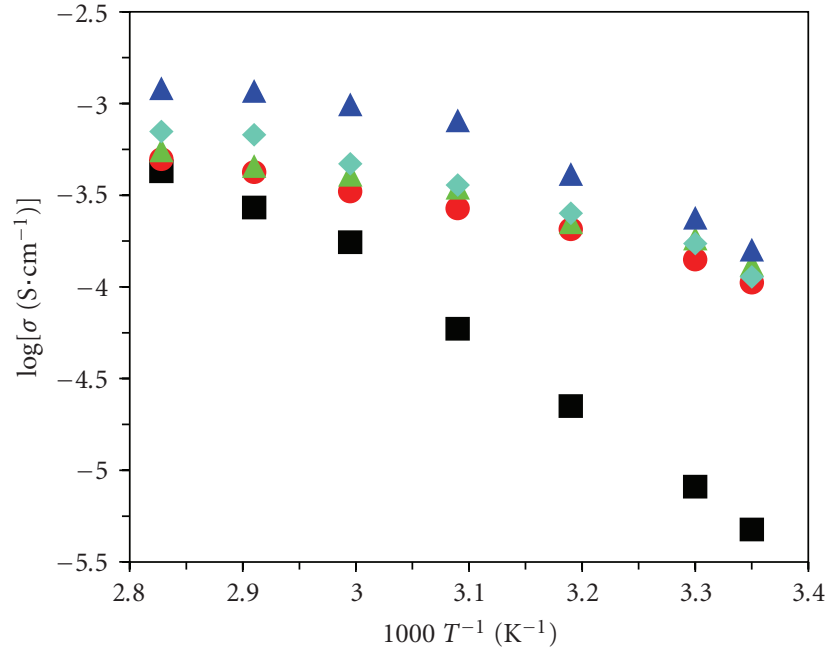
- $x=0$
- $x=5$
A $x=15$

$\triangle x=10$

Figure 7: Temperature dependence of ionic conductivity of PMMA-based GPE with different filler-loading contents. (a) PMMA/PC/ $\mathrm{LiClO}_{4} /$ bare OMS $(100 / 30 / 50 / x, w / w / w / w)$; (b) PMMA/PC/LiClO $4 / O M S-g-P M M A ~(100 / 30 / 50 / x, w / w / w / w)$.

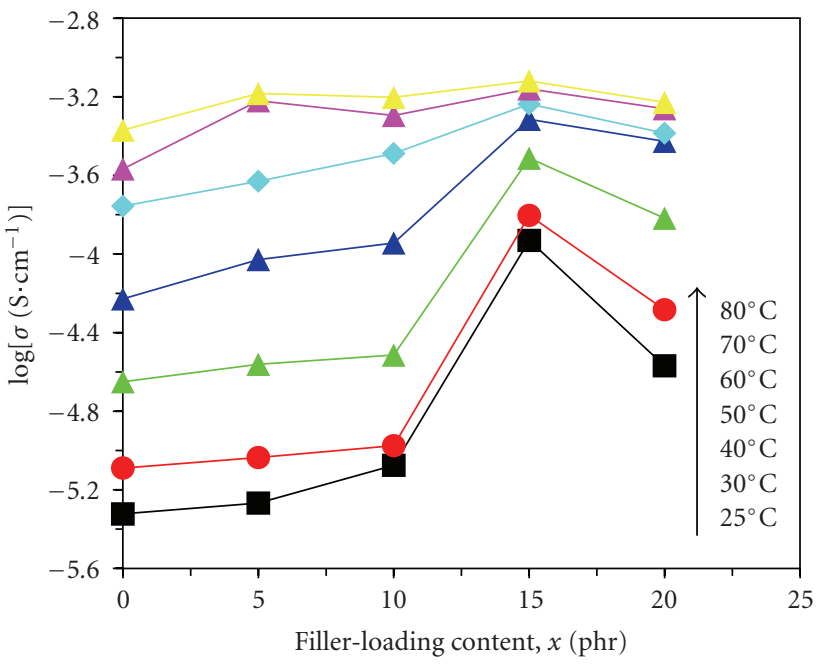

(a)

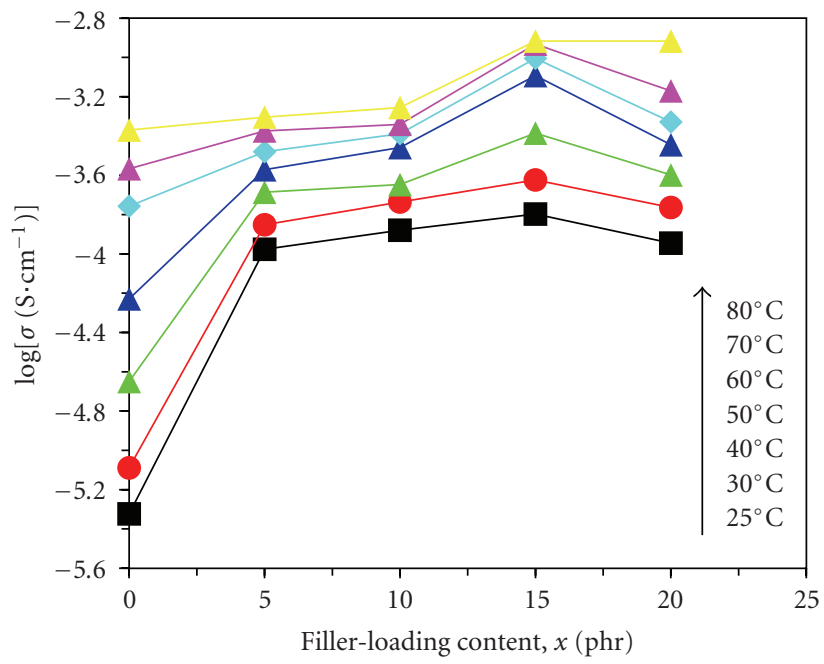

(b)

Figure 8: Ionic conductivity of PMMA-based GPE as a function of filler-loading content. (a) PMMA/PC/ $\mathrm{LiClO}_{4} / \mathrm{OMS}(100 / 30 / 50 / x$, $w / w / w / w)$; (b) PMMA/PC/LiClO $4 /$ OMS-g-PMMA $(100 / 30 / 50 / x, w / w / w / w)$. For (b), the $x$ is the actual mass of OMS contained in the OMSg-PMMA.

TABLE 1: Ionic conductivity of PMMA-based GPE with different filler-loading content at $25^{\circ} \mathrm{C}$.

\begin{tabular}{|c|c|c|c|c|c|}
\hline \multirow{2}{*}{ Sample } & \multicolumn{5}{|c|}{$\sigma\left(\times 10^{-6} \mathrm{~S} \cdot \mathrm{cm}^{-1}\right)$} \\
\hline & $x=0$ & $x=5$ & $x=10$ & $x=15$ & $x=20$ \\
\hline PMMA/PC/LiClO $4 /$ bare OMS $(100 / 30 / 50 / x, w / w / w / w)$ & 4.76 & 5.41 & 8.41 & 117.26 & 26.99 \\
\hline PMMA/PC/LiClO $4 /$ OMS-g-PMMA $(100 / 30 / 50 / x, w / w / w / w)$ & 4.76 & 105.61 & 132.01 & 159.41 & 113.40 \\
\hline
\end{tabular}


TABLE 2: Ionic conductivity of PMMA-based GPE under different temperature at a filler-loading content of 15 phr.

\begin{tabular}{|c|c|c|c|c|c|c|c|}
\hline \multirow{2}{*}{ Sample } & \multicolumn{7}{|c|}{$\sigma\left(\times 10^{-4} \mathrm{~S} \cdot \mathrm{cm}^{-1}\right)$} \\
\hline & $25^{\circ} \mathrm{C}$ & $30^{\circ} \mathrm{C}$ & $40^{\circ} \mathrm{C}$ & $50^{\circ} \mathrm{C}$ & $60^{\circ} \mathrm{C}$ & $70^{\circ} \mathrm{C}$ & $80^{\circ} \mathrm{C}$ \\
\hline PMMA/PC/ $\mathrm{LiClO}_{4} / \mathrm{OMS}(100 / 30 / 50 / 15, w / w / w / w)$ & 1.17 & 1.57 & 3.07 & 4.85 & 5.80 & 6.92 & 7.60 \\
\hline PMMA/PC/LiClO $4 / \mathrm{OMS}-\mathrm{g}-\mathrm{PMMA}(100 / 30 / 50 / 15, w / w / w / w)$ & 1.59 & 2.38 & 4.12 & 8.08 & 9.88 & 11.70 & 12.10 \\
\hline
\end{tabular}

TABLE 3: Mechanical properties of PMMA-based GPE membranes.

\begin{tabular}{|c|c|c|c|}
\hline Sample & Tensile strength (MPa) & Modulus (MPa) & Elongation $(\%)$ \\
\hline $\mathrm{PMMA} / \mathrm{PC} / \mathrm{LiClO}_{4}(100 / 30 / 50, w / w / w)$ & 0.59 & 0.22 & 75.19 \\
\hline PMMA/PC/LiClO $4 /$ bare OMS $(100 / 30 / 50 / 15, w / w / w / w)$ & 0.96 & 0.49 & 60.65 \\
\hline PMMA/PC/LiClO $4 /$ OMS-g-PMMA $(100 / 30 / 50 / 15, w / w / w / w)$ & 2.01 & 0.75 & 86.52 \\
\hline
\end{tabular}

As shown in Figure 8(b), the conductivity of the OMS-gPMMA filled system increases with filler-loading content and a highest conductivity was gained at $15 \mathrm{phr}$ OMS-g-PMMA loading content followed by decrease in conductivity with further increase in filler-loading content, which is totally similar to the bare OMS filled system. However, it is noteworthy that at $25^{\circ} \mathrm{C}$ the conductivity for the OMS-g-PMMA filled system is always higher than that of the bare OMS filled system corresponding to the whole filler-loading content range as shown in Table 1. Moreover, the conductivity for the OMS-g-PMMA filled system gained a higher value $(1.06 \times$ $10^{-4} \mathrm{~S} \cdot \mathrm{cm}^{-1}$ ) only when $5 \mathrm{phr}$ OMS-g-PMMA was added, which is comparable to that $\left(1.17 \times 10^{-4} \mathrm{~S} \cdot \mathrm{cm}^{-1}\right)$ for the bare OMS-filled system corresponding to $15 \mathrm{phr}$ fillerloading content. This indicates that it is easier, for the OMSg-PMMA filled system, to form an ions transferring network at a lower filler-loading content compared to the bare OMS filled system, which might be due to the highly improved interfacial compatibilization between the OMS and PMMA matrix resulting from surface-modification of OMS through surface-initiated ATRP of MMA. Similarly, it is also found from Table 2 that the conductivity for the OMS-g-PMMA filled system is always higher than that for the bare OMS filled system at the same filler-loading content (15 phr) corresponding to the whole temperature range from $25^{\circ} \mathrm{C}$ to $80^{\circ} \mathrm{C}$.

3.3. Thermal Properties. The thermal properties of the PMMA-based GPE filled with the bare OMS and OMS-gPMMA, respectively, were characterized by DSC. The effect of fillers on improving the thermal properties of both systems was evaluated. Figures 9(a) and 9(b) illustrates and compares the DSC curves for both systems under different filler-loading content. For the purpose of comparison, the DSC curve for the pure PMMA as GPE matrix is also represented in above figure. As shown in Figure 9(a), the pure PMMA exhibits a higher glass-transition temperature $\left(T_{g}, 106.3^{\circ} \mathrm{C}\right)$ due to the higher stiffness of chains. With the addition of $\mathrm{LiClO}_{4}$ and plasticizer, PC, the $T_{g}$ for the filler-free sample $(x=0)$ is decreased to $103.4^{\circ} \mathrm{C}$ with a slight drop about $3^{\circ} \mathrm{C}$ compared to the pure PMMA. However, a gradual improvement in $T_{g}$ is observed when the bare OMS of different loading contents was added, showing the effect of
OMS filler. The $T_{g}$ for the sample $(x=10)$ containing $10 \mathrm{phr}$ bare OMS increases to $110.1^{\circ} \mathrm{C}$, which is higher than that of the filler-free sample $\left(103.4^{\circ} \mathrm{C}\right)$ and even the pure PMMA $\left(106.3^{\circ} \mathrm{C}\right)$. Such an improvement in $T_{g}$ might be attributed to the characteristic nanoporous structure of OMS particles, which is expected to reduce the mobility of PMMA chains by imbedding the PMMA chains into pore channel under sonication condition. Similarly, a greater improvement in $T_{g}$ was detected, for the OMS-g-PMMA filled GPE system, with the introduction of the OMS-g-PMMA core-shell particles as shown in Figure $9(\mathrm{~b})$. A maximum $\left(118.9^{\circ} \mathrm{C}\right)$ in $T_{g}$ was gained corresponding to $15 \mathrm{phr}$ filler-loading content $(x=$ 15), which is considerably higher, by $15.5^{\circ} \mathrm{C}$ and $12.6^{\circ} \mathrm{C}$, than that of the free-filler sample and pure PMMA, respectively. The explanation for this is maybe due to the characteristic core-shell hybrid structure of the OMS-g-PMMA, in which the PMMA shell grafted onto the exterior surface of OMS core may entangle with the PMMA matrix and thus can highly improve the interfacial compatibilization between the OMS particles with PMMA matrix. As a result, the $T_{g}$ of system will be considerably improved due to the reduction in mobility of PMMA chains resulting from the entangled structure mentioned as above.

3.4. Mechanical Properties. One of the major drawbacks associated with GPE is the poor mechanical properties due to the addition of excess plasticizer into polymer matrix. Incorporating various types of inorganic nanofillers into polymer matrix to prepare the composite GPE (NGPE) is one of the effective approaches for improving the mechanical properties of GPE. The effect of the OMS-g-PMMA on the mechanical properties of the PMMA-based GPE is examined by tensile testing. The stress-strain curves for the PMMA-based GPE filled with $15 \mathrm{phr}$ of OMS-g-PMMA is shown in Figure 10 and the tensile properties are given in Table 3 . The mechanical properties of the GPE filled with $15 \mathrm{phr}$ of bare OMS and the filler-free GPE sample are also given in Figure 10 and Table 3 for comparison. As can be seen the introduction of the bare OMS (15 phr) improves, to an extent, the tensile strength and Young's modulus of the PMMA-based GPE while decreasing slightly the elongation at break. Compared to the filler-free GPE sample, the tensile strength increases by 


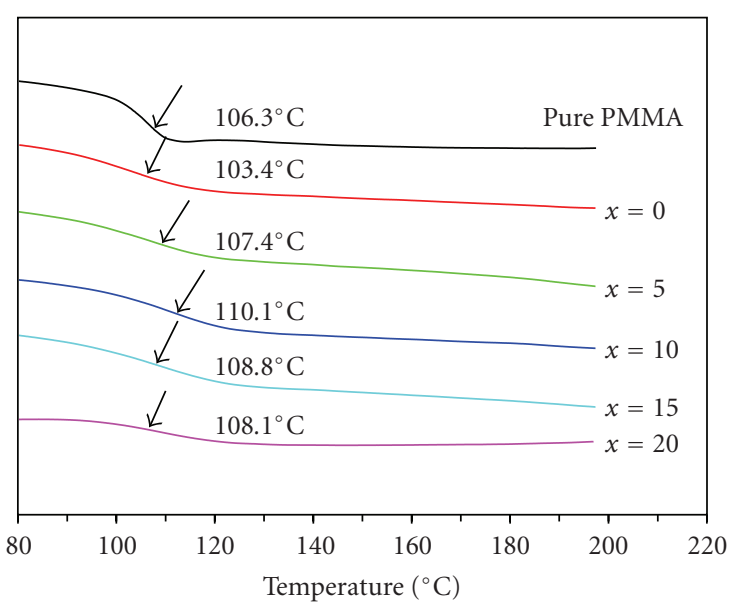

(a)

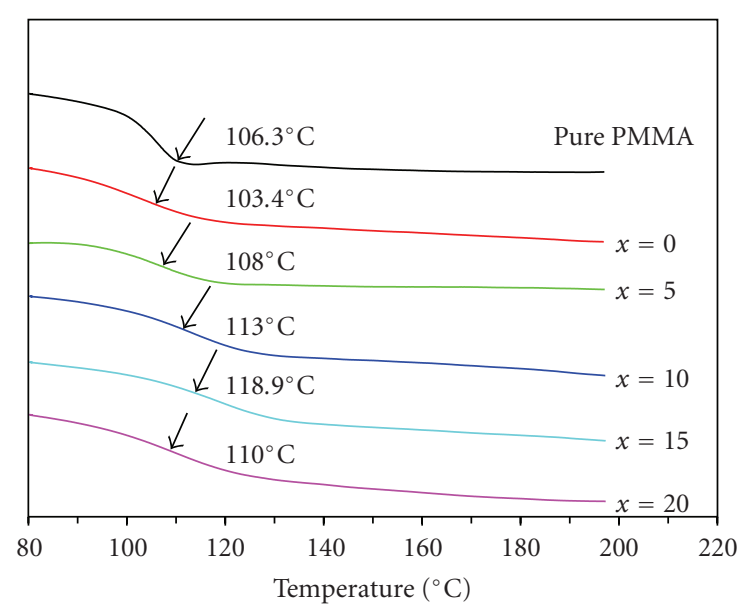

(b)

FIGURE 9: Differential scanning calorimetry (DSC) curves of (a) PMMA/PC/LiClO $4 /$ bare OMS (100/30/50/x, w/w/w/w) and (b) PMMA/ $\mathrm{PC} / \mathrm{LiClO}_{4} / \mathrm{OMS}-\mathrm{g}-\mathrm{PMMA}(100 / 30 / 50 / x, w / w / w / w)$. Here, $x$ changed from 0 to 20 . For (b), the $x$ is the actual mass of OMS contained in the OMS-g-PMMA.

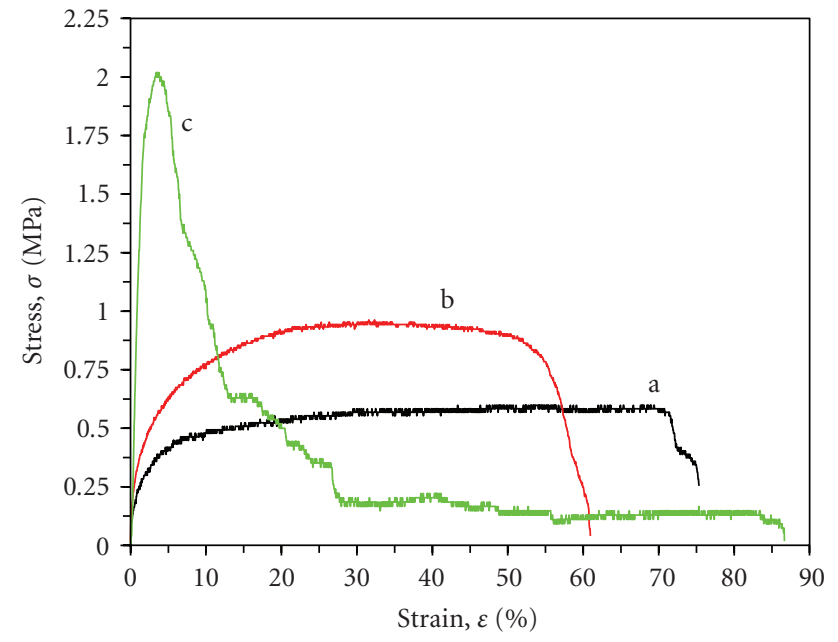

FIGURE 10: Stress-strain curves of PMMA-based GPE. (a) PMMA/PC/LiClO $4(100 / 30 / 50, w / w / w) ;\left(\right.$ b) $\mathrm{PMMA} / \mathrm{PC} / \mathrm{LiClO}_{4} /$ bare OMS $(100 / 30 / 50 / 15, w / w / w / w)$; (c) PMMA/PC/LiClO $4 / \mathrm{OMS}-$ g-PMMA $(100 / 30 / 50 / 15, w / w / w / w)$.

$62.7 \%$ and the modulus by $123.0 \%$. In the case of the OMS-gPMMA-filled GPE sample, a more significant enhancement in mechanical properties was observed compared to the bare OMS filled GPE sample. The tensile strength and modulus reach $2.01 \mathrm{MPa}$ and $0.75 \mathrm{MPa}$, respectively, which is higher by 2.39 times and 2.41 times, respectively, compared to that of the filler-free sample. This indicates that the mechanical properties of the PMMA-based GPE could be effectively improved by adding the core-shell PMMA-grafted OMS into PMMA matrix, which is consistent with the results on DSC analysis that introducing OMS-g-PMMA into PMMA matrix considerably increases the $T_{g}$ of GPE. The characteristic core-shell structure of the OMS-g-PMMA particles should be responsible for above improvement both in $T_{g}$ and in mechanical properties of PMMA-based GPE.

\section{Conclusion}

The core-shell PMMA-grafted OMS hybrid particle has been successfully synthesized by surface-initiated ATRP of MMA. FTIR, TGA, SAXRD, and HRTEM analysis confirm that the resulting OMS-g-PMMA possesses typical core-shell structure, in which a homogeneous PMMA shell is chemically bonded to the exterior surface of the OMS as a core retaining intact MCM-41 type mesoporous structure. The characteristic core-shell OMS-g-PMMA is found, as a filler, to more effectively improve the ionic conductivity of the PMMAbased GPE compared to the bare OMS. AC impedance measurements show that the temperature dependence of ionic conductivity for the PMMA-based GPE filled with OMS-gPMMA exhibits VTF behavior, and a maximum in conductivity $\left(1.59 \times 10^{-4} \mathrm{~S} \cdot \mathrm{cm}^{-1}, 25^{\circ} \mathrm{C}\right)$ could be gained at $15 \mathrm{phr}$ filler-loading content, which is higher by nearly two orders than that of the filler-free PMMA-based GPE. Moreover, the results on DSC and tensile testing indicate that the mechanical properties of the PMMA-based GPE could be greatly improved by adding the OMS-g-PMMA to matrix, with a considerable enhancement in $T_{g}\left(\sim 15.5^{\circ} \mathrm{C}\right)$. The tensile strength increased by 2.39 times and Young's modulus by 2.41 times, compared to the filler-free PMMA-based GPE, at 15 phr filler-loading content. The excellent comprehensive properties make the PMMA-based GPE filled with OMS-gPMMA prospective for lithium batteries and other electrochemical devices.

\section{Acknowledgments}

The authors would like to acknowledge the financial support from the National Nature Science Fund of China (21074117) and appreciate the support of the Key Research Project (no. 2008C01021-2) from Science and Technology Department of Zhejiang Province. 


\section{References}

[1] Y. Wang, X. Ma, Q. Zhang, and N. Tian, "Synthesis and properties of gel polymer electrolyte membranes based on novel comb-like methyl methacrylate copolymers," Journal of Membrane Science, vol. 349, no. 1-2, pp. 279-286, 2010.

[2] S. Rajendran, V. S. Bama, and M. R. Prabhu, "Effect of lithium salt concentration in PVAc/PMMA-based gel polymer electrolytes," Ionics, vol. 16, no. 1, pp. 27-32, 2010.

[3] Y. Liao, M. Rao, W. Li, C. Tan, J. Yi, and L. Chen, "Improvement in ionic conductivity of self-supported P(MMA-ANVAc) gel electrolyte by fumed silica for lithium ion batteries," Electrochimica Acta, vol. 54, no. 26, pp. 6396-6402, 2009.

[4] Q. Xiao, Z. Li, D. Gao, T. He, and H. Zhang, "Preparation and electrochemical performance of gel polymer electrolytes with a novel star network," Journal of Applied Electrochemistry, vol. 39, no. 2, pp. 247-251, 2009.

[5] L. Othman, K. W. Chew, and Z. Osman, "Impedance spectroscopy studies of poly (methyl methacrylate)-lithium salts polymer electrolyte systems," Ionics, vol. 13, no. 5, pp. 337 342, 2007.

[6] D. Shanmukaraj, G. X. Wang, R. Murugan, and H. K. Liu, "Ionic conductivity and electrochemical stability of poly(methylmethacrylate)-poly(ethylene oxide) blendceramic fillers composites," Journal of Physics and Chemistry of Solids, vol. 69, no. 1, pp. 243-248, 2008.

[7] J. P. Sharma and S. S. Sekhon, "Nanodispersed polymer gel electrolytes: conductivity modification with the addition of PMMA and fumed silica," Solid State Ionics, vol. 178, no. 5-6, pp. 439-445, 2007.

[8] S. Ahmad, S. Ahmad, and S. A. Agnihotry, "Nanocomposite electrolytes with fumed silica in poly(methyl methacrylate): thermal, rheological and conductivity studies," Journal of Power Sources, vol. 140, no. 1, pp. 151-156, 2005.

[9] Y. X. Jiang, Z. F. Chen, Q. C. Zhuang et al., "A novel composite microporous polymer electrolyte prepared with molecule sieves for Li-ion batteries," Journal of Power Sources, vol. 160, no. 2, pp. 1320-1328, 2006.

[10] J. Xi, X. Qiu, M. Cui, X. Tang, W. Zhu, and L. Chen, "Enhanced electrochemical properties of PEO-based composite polymer electrolyte with shape-selective molecular sieves," Journal of Power Sources, vol. 156, no. 2, pp. 581-588, 2006.

[11] F. Chen, X. Ma, X. Qu, and H. Yan, "Structure and properties of an organic rectorite/poly(methyl methacrylate) nanocomposite gel polymer electrolyte by in situ synthesis," Journal of Applied Polymer Science, vol. 114, no. 5, pp. 2632-2638, 2009.

[12] O. Krejza, J. Velická, M. Sedlař́ková, and J. Vondrák, “The presence of nanostructured $\mathrm{Al}_{2} \mathrm{O}_{3}$ in PMMA-based gel electrolytes," Journal of Power Sources, vol. 178, no. 2, pp. 774-778, 2008.

[13] S. Ahmad, T. K. Saxena, S. Ahmad, and S. A. Agnihotry, "The effect of nanosized $\mathrm{TiO}_{2}$ addition on poly(methylmethacrylate) based polymer electrolytes," Journal of Power Sources, vol. 159, no. 1, pp. 205-209, 2006.

[14] S. H. Chung, L. Persi, F. Croce, S. G. Greenbaum, B. Scrosati, and E. Plichta, "Enhancement of ion transport in polymer electrolytes by addition of nanoscale inorganic oxides," Journal of Power Sources, vol. 97-98, pp. 644-648, 2001.

[15] F. Croce, L. L. Persi, B. Scrosati, F. Serraino-Fiory, E. Plichta, and M. A. Hendrickson, "Role of the ceramic fillers in enhancing the transport properties of composite polymer electrolytes," Electrochimica Acta, vol. 46, no. 16, pp. $2457-$ 2461, 2001.
[16] M. J. Reddy and P. P. Chu, "7Li NMR spectroscopy and ion conduction mechanism in mesoporous silica (SBA-15) composite poly(ethylene oxide) electrolyte," Journal of Power Sources, vol. 135, no. 1-2, pp. 1-8, 2004.

[17] S. Kim, E. J. Hwang, and S. J. Park, "An experimental study on the effect of mesoporous silica addition on ion conductivity of poly(ethylene oxide) electrolytes," Current Applied Physics, vol. 8, no. 6, pp. 729-731, 2008.

[18] J. Xi, S. Miao, and X. Tang, "Selective transporting of lithium ion by shape selective molecular sieves ZSM-5 in PEO-based composite polymer electrolyte," Macromolecules, vol. 37, no. 23, pp. 8592-8598, 2004.

[19] Ch. V. Subba Reddy, G. P. Wu, C. X. Zhao, Q. Y. Zhu, W. Chen, and R. R. Kalluru, "Characterization of SBA-15 doped (PEO + $\mathrm{LiClO}$ ) polymer electrolytes for electrochemical applications," Journal of Non-Crystalline Solids, vol. 353, no. 4, pp. 440-445, 2007.

[20] J. Xi, X. Qiu, X. Ma et al., "Composite polymer electrolyte doped with mesoporous silica SBA-15 for lithium polymer battery," Solid State Ionics, vol. 176, no. 13-14, pp. 1249-1260, 2005.

[21] X. L. Wang, A. Mei, M. Li, Y. Lin, and C. W. Nan, "Effect of silane-functionalized mesoporous silica SBA-15 on performance of PEO-based composite polymer electrolytes," Solid State Ionics, vol. 177, no. 15-16, pp. 1287-1291, 2006.

[22] Y. Yang, X. Yan, Y. Cui et al., "Preparation of polymer-coated mesoporous silica nanoparticles used for cellular imaging by a "graft-from" method," Journal of Materials Chemistry, vol. 18, no. 47, pp. 5731-5737, 2008.

[23] C. F. Cheng, H. H. Cheng, PO. W. Cheng, and Y. J. Lee, "Effect of reactive channel functional groups and nanoporosity of nanoscale mesoporous silica on properties of polyimide composite," Macromolecules, vol. 39, no. 22, pp. 7583-7590, 2006. 

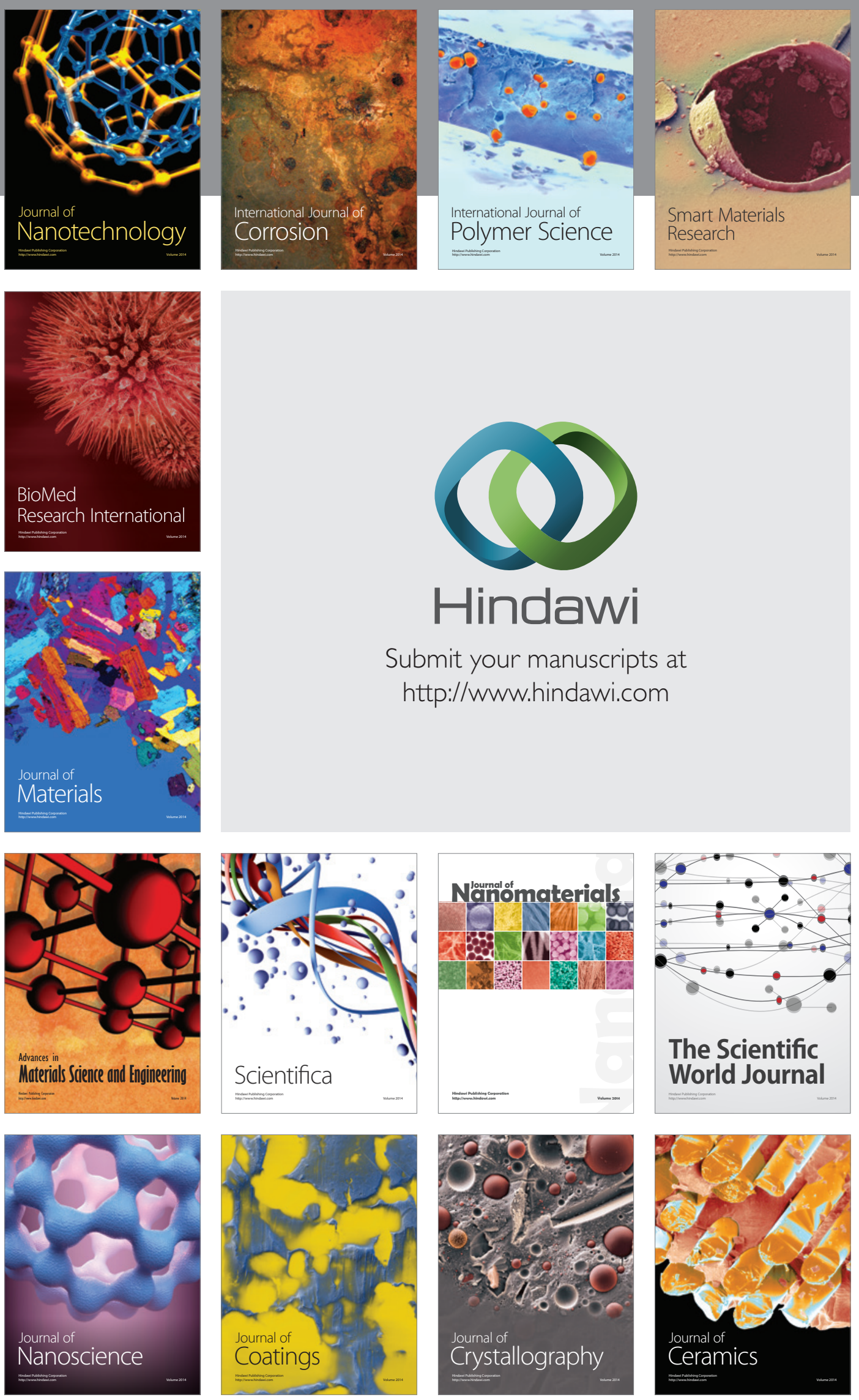

The Scientific World Journal

Submit your manuscripts at

http://www.hindawi.com

\section{World Journal}

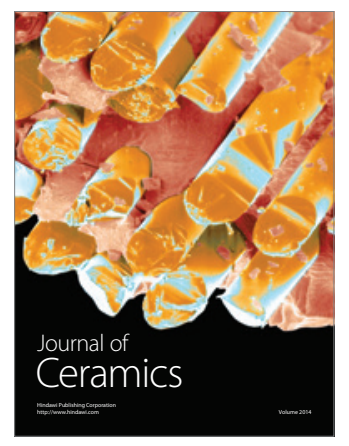

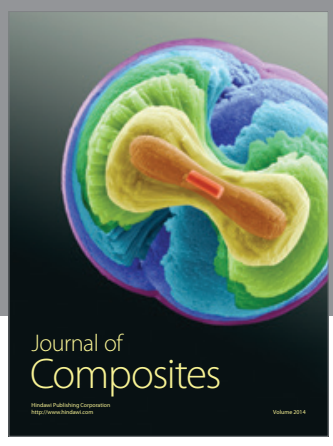
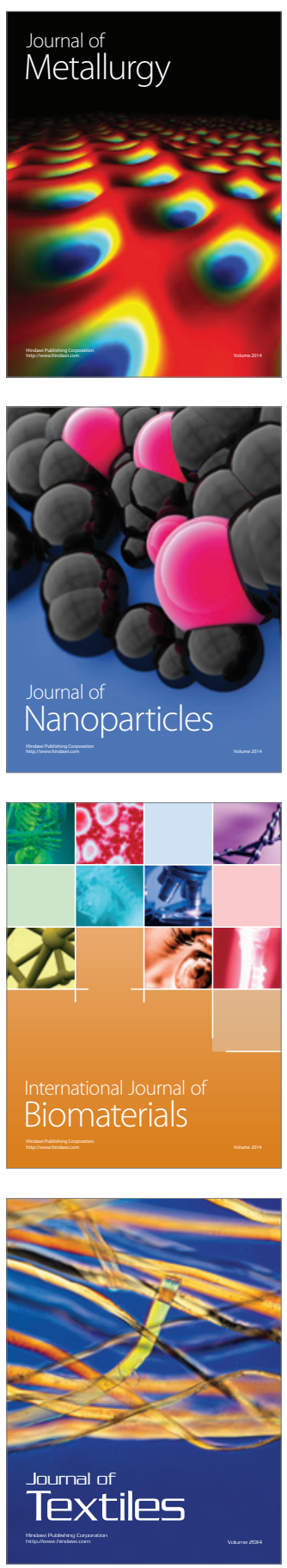